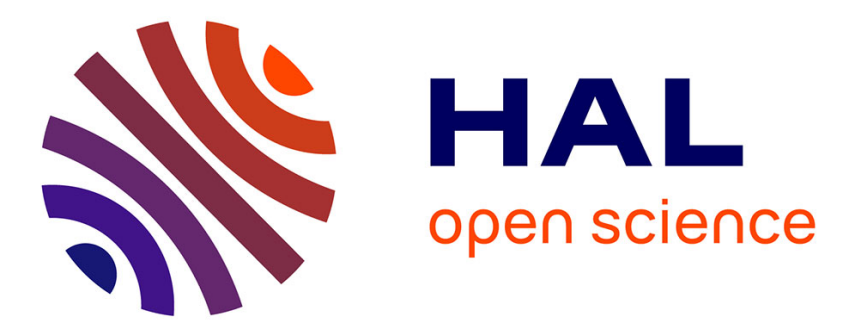

\title{
Cooperation between Medicine and Sociology in Head and Neck Oncology
}

\author{
Emmanuel Babin, Guillaume Grandazzi
}

\section{To cite this version:}

Emmanuel Babin, Guillaume Grandazzi. Cooperation between Medicine and Sociology in Head and Neck Oncology. Otolaryngology - Head and Neck Surgery, 2014, 150 (5), pp.712-715. 10.1177/0194599814521783 . hal-02130273

\section{HAL Id: hal-02130273}

\section{https://hal-normandie-univ.archives-ouvertes.fr/hal-02130273}

Submitted on 19 May 2019

HAL is a multi-disciplinary open access archive for the deposit and dissemination of scientific research documents, whether they are published or not. The documents may come from teaching and research institutions in France or abroad, or from public or private research centers.
L'archive ouverte pluridisciplinaire HAL, est destinée au dépôt et à la diffusion de documents scientifiques de niveau recherche, publiés ou non, émanant des établissements d'enseignement et de recherche français ou étrangers, des laboratoires publics ou privés. 


\title{
Otolaryngology-Head and Neck Surgery 2014, Vol. 150(5) 712-715
}

\section{Cooperation between Medicine and Sociology in Head and Neck Oncology}

Emmanuel Babin, MD, PhD and Guillaume Grandazzi, PhD

\begin{abstract}
Twenty-first-century medicine is facing many challenges-knowledge and command of technical advances, research development, team management, knowledge transmission, and adaptation to economic constraints-without neglecting "human" aspects, via transformed carer-patient relationships, social change, and so on. The "modern" physicians know that simply treating disease is no longer enough. One of their essential missions lies in offering the individual patient overall care, which implies acknowledging the latter as an individual within a family, social, and professional environment. Indeed, medical practice requires pluridimensional knowledge of the patients' experience of their disease. Yet the contribution sociology can offer to health care remains largely unknown to many physicians, and medical training includes only limited instruction in the human sciences. On the basis of a few observations taken from sociological research, we would like to demonstrate how, in head and neck oncology, interdisciplinary collaboration between medicine and sociology can prove propitious to improving patient care and attention to their close relations.
\end{abstract}

\section{Keywords}

sociability, head and neck cancers, quality of life 
Modern medical practice requires pluridimensional knowledge of the patients' experience of their disease: not only knowledge of the pathology but also acute understanding of what being ill can represent for individuals and their close relatives, together with knowl-edge of the social and institutional stakes involved. The contribution of sociology and social sciences deserves more attention at all levels of medical education. On the basis of observations taken from sociological research, we would like to demonstrate the potential for interdisciplinary colla-boration in head and neck oncology.

\section{Medical Sociology and Oncology: Five Observations}

Over the second half of the 20th century, cancer was often treated by physicians as an acute disease, while being increasingly experienced by patients as a chronic process. Cancer can no longer be exclusively associated with a simple biological dysfunction. First observation: The carer-patient duo has evolved from submission to participation, or even therapeutic co-decision.

A second change in the health care model in cancer care involves a shift in the location of delivery of health care ser-vices. For many decades, cancer care was hospital based. A great share of the patients' experience of disease is now out-side of the health care establishment and part of their day-to-day life and that of family caregivers. Second observation: The geographical focal point of chronic cancer care is no longer exclusively the hospital but also the patient's home.

From a medical point of view, cancer was henceforth experienced as an evolution in symptoms from diagnosis to remission or death. From a sociological angle, the notion of illness trajectory, introduced by Corbin and Strauss (1), offered a more comprehensive view of illness. Of course, the concept of trajectory encompasses not only the physiological development of disease but also the overall organizational effort deployed by the various players involved throughout disease monitoring and control. This effort includes the many activities undertaken not only by carers but also by patients themselves or by their close relations. This "unending work" (1) is not limited to simply providing health care but also involves reorganizing the many dimensions of daily life and the necessary biographical adjustments.

The work accomplished by professional care teams is, in turn, not limited to technical care but also requires personal commitment to explain disease, to listen to and reassure the patient and those who are part of his or her daily life. Third observation: The patient's experience encompasses a combination of disease evolution from a biological point of view and the many medical and paramedical activities that punctuate and alter this evolution, combining to form the illness trajectory.

The contribution that sociology can bring to cancer care enables us to surpass our customary medical prerogatives. Of course, recovery (remission) remains the main aim of medical care, followed by the secondary aim of monitoring and controlling evolution, symptoms, and their consequence. Care teams must consider the work involved in managing the new lifestyle conditions that are generated by illness: transformed social roles, responsibilities, modified family relationships, and so on. Fourth observation: Sociology also incites us not to focus exclusively on disease but to broaden our outlook to encompass the individual and social repercussions associated with cancer and its treatment.

Families, for a long time ignored or considered a problem by carers or even qualified as "pathological," nevertheless can still prove embarrassing for medical staff when recovery is not a foreseeable outcome or when therapeutic inaction is interpreted as patient abandonment. Since the 1980s to 1990s, attention has focused more specifically on the support and social care role played by families and on the help (emotional, cognitive, material, normative) that close relations can provide to patients. More recently, families have 
received attention as "collateral victims" of disease. The suffering generated by cancer and the burden of disease lead to exhaustion among family caregivers. Fifth observation: The status of family caregivers has changed from that of occasionally problematic helpers to participants or even victims (see Table 1).

Table 1. Five Observations from Sociological Research and Their Implications for Head and Neck Oncology

Observations

Implications

\begin{tabular}{|l|l|}
\hline $\begin{array}{l}\text { Change from paternalistic practice to involvement } \\
\text { of patients and caregivers in therapeutic decision } \\
\text { and patient care }\end{array}$ & $\begin{array}{l}\text { Increasing dislike for paternalism in medical } \\
\text { interactions has called into question the "doctor } \\
\text { knows best" model }\end{array}$ \\
\hline $\begin{array}{l}\text { Move from hospital to home: shift in the location } \\
\text { where most medical services are provided }\end{array}$ & $\begin{array}{l}\text { Need to strengthen town-hospital links to improve } \\
\text { help, follow-up, and support for patients and their } \\
\text { close relations, as well as dialogue between health } \\
\text { care professionals }\end{array}$ \\
\hline $\begin{array}{l}\text { From disease evolution to illness trajectory: a } \\
\text { more comprehensive view of the patient's } \\
\text { experience }\end{array}$ & $\begin{array}{l}\text { Recognizing the importance of the patient's } \\
\text { experience of the illness and his or her } \\
\text { involvement in the management of the illness } \\
\text { trajectory }\end{array}$ \\
\hline $\begin{array}{l}\text { Importance of the work involved in managing new } \\
\text { lifestyle conditions at home. The cancer patient is } \\
\text { not just a sick individual but a person living within } \\
\text { a family, social, and economic context. }\end{array}$ & $\begin{array}{l}\text { Being sensitive to psychosocial consequences } \\
\text { owing to the biographical disruption and the } \\
\text { identity-related metamorphoses associated with } \\
\text { illness and its treatment: toward a more holistic } \\
\text { patient care }\end{array}$ \\
\hline $\begin{array}{l}\text { The role of family caregivers and its evolution: } \\
\text { recognizing that they are central players in patient } \\
\text { care }\end{array}$ & $\begin{array}{l}\text { Family caregivers must not be overlooked as not } \\
\text { the patient and thus not in need of aid and support } \\
\text { by medical professionals }\end{array}$ \\
\hline
\end{tabular}

\section{Medical Sociology and Head and Neck Oncology}

In the field of head and neck oncology, disease and its treatment alter the individual's physiological functions. Breathing is often difficult secondary to tracheobronchial obstruction. Deglutition is delicate, since radiotherapy deprives the individual of saliva. Radiation treatment associated with sometimes mutilating surgery alters patients' sense of taste and smell. Swallowing is often associated with pain similar to burns. Eating is no longer synonymous with pleasure, all the more so since food is more often than not blended.

In most cases, radiotherapy also requires multiple dental extractions. Dental rehabilitation via dental implants is often performed late and proves difficult to bear for patients, hence explaining the choice for semi-liquid feeding. Hearing inevitably deteriorates over time, yet impairment can also be precipitated if the patient has benefited from ototoxic (toxic for the ear) chemotherapy and/or radiotherapy. Phonation is modified due to the partial or total amputation of laryngeal structures and/or radiotherapy-associated modifications to mucous membranes. Loss of original voice is one of the major factors impairing quality of life (2). 
From a sociological point of view, the patient with head and neck cancer is considered an individual living within an emotional, social, and professional environment. His or her life path inexorably declines, via acute and/or chronic periods. The clinical and biological dysfunction caused by cancer is accompanied by a number of repercussions on the patient's day-to-day life. Physical alterations also engender individual transformation. The most evident illustration lies in the consequences of the disease on the face, a feature that is inseparable from our personal identity.

In head and neck oncology, the patient's face is wounded or deformed after maiming surgery such as buccopharyngectomy. The neck is scored with scars from lymph node dissection or following thracheotomy. The term mutilation is even used in reference to tracheostomy, subsequent to total laryngectomy. It induces a process of stigmatization (3). Stigma is an attribute that the individual has but would rather not. In the case in question, this includes the cosmetic and functional sequelae associated with cancer and treatments. Stigma translates particularly in terms of social repercussion and patients are marginalized.

The change in self-presentation generated by cancer alters the relationships that others (healthy relations) have with the patient. These relationships are generally tense, embarrassing, and doubtful. In day-to-day situations, often neither party knows quite how the other will react, and most of the time, encounters are curtailed or even avoided. Yet, whereas cancer has simply altered the individual's physical functions, patients with cancer are victims of appearance-related disability.

However important it is to inform patients that they are individuals like any other, that their dignity and personal value are in no way called into question through their altered physical state, they are more or less kept at a distance from ordinary life. The consequences of disease and its treatment are indisputably factors that limit social relationships. This situation drives individuals into self-confinement. Altered selfesteem and the behavior of others stir up feelings of solitude. This is a well-known phenomenon among the disabled (4). The patient avoids exclusion from social life via close relations and carers, two "wise person" groups (3) on the reality of disease and on the patient's day-to-day lives. They collectively form the patient's intimate circle. They play multiple roles covering support, help, protection, and defense.

The patient's spouse plays an essential role. Most patients with head and neck cancer are men and former workers or laborers. Transformation in social roles is one of the first disease-related phenomena to emerge: the spouse becomes the dominating individual, the head of the family. She ensures her husband's protection, warns him of temptations associated with alcohol and tobacco, and filters encounters with others, particularly with former work colleagues. The family then extends this action. It forms the ramparts of the fortification within which the sick individual organizes his or her living space.

The role of carers, exhausted by the weight of head and neck cancer care, is also important. Patients themselves are in the best position to talk of them: "When I come to the department, I see Delphine, the nurse, or Irene, the auxiliary. I talk to them about everything and nothing. They are different from people I see outside. I'm no longer of any interest to the guys I used to work with. Probably because we have nothing much in common anymore. Here, with the staff, I feel like I still exist a little." This patient narrative illustrates how difficult it is to preserve links after cancer, which adjourns certain aspects of life via the loss of professional activity and gradually leads to social death (5). Hospital-based carers can sometimes constitute the patient's second family, hence preventing family isolation by offering them a place where they feel neither judged nor stigmatized. 


\section{Conclusion}

Observations in medical sociology applied to head and neck cancer call for a reaction by physicians. In our hospital, we have developed and personalized the initial cancer consultation, during which patients learn their diagnosis, and linked it to a multidisciplinary program. We acknowledge that it is very difficult to explain a surgical procedure and all of its medical and nonmedical consequences during a 15-minute appointment. This difficulty is increased when surgery is likely to be mutilating.

Patients are informed of diagnosis and recommended treatment after the multidisciplinary meeting. They are invited to return the following week in the company of their spouse or a relative. At that time, they meet their attending otolaryngologist in a room specially designed for this type of consultation. During the initial consultation, the physician is accompanied by a trained hospital nurse, a dietitian, a speech therapist, and a social worker. A representative from the laryngectomized patients association may also join the team or meet with the patient at a later date. Each member of the team conveys his or her own message with regard to surgery and its consequences and remains available to answer any questions the patient or his or her close relations may have.

Collaboration between sociologists and physicians has contributed toward transforming cancer patient care by inviting physicians to broaden their outlook on their patients' lives. Knowledge of their social environment is fundamental. The individual is not just a sick patient but a person, living within a family, social, and economic context.

Patient remission-recovery remains the key expectation for physicians. Guaranteeing patients a decent quality of life must also be among their priority goals. Such action does not exclusively rely on their intervention on the patient's body, for the notion of healing cannot be reduced to the simple absence of disease. Offering the rehabilitated patient a return to society requires both technical skills and extensive understanding of the psychosocial dimensions of dis-ease, hence enabling a truly pluridisciplinary approach to overall patient care. Our own practice in head and neck cancer bears witness to the benefits of such collaboration between medicine and the human sciences.

\section{Author Contributions}

Emmanuel Babin, analysis and interpretation of data, drafting the article, final approval of the version to be published; Guillaume Grandazzi, analysis and interpretation of data, revising the article for important intellectual content, final approval of the version to be published.

\section{References}

1. Corbin J, Strauss A. Unending Work and Care: Managing Chronic Illness at Home. San Francisco, CA: Jossey-Bass; 1988.

2. Babin $E$, Sigston $E$, Hitier $M$, et al. Quality of life in head and neck cancers patients: predictive factors, functional and psycho-social outcome. Eur Arch Otorhinolaryngol. 2008;265:265-270.

3. Goffman E. Stigma: Notes on the Management of Spoiled Identity. New York: Simon \& Schuster/Touchstone Books; 1963.

4. Murphy RF. The Body Silent: A Journey into Paralysis. New York: Henry Holt; 1987. 
5. Babin E, Blanchard D, Hitier M. Management of total laryngect-omy patients over time: from the consultation announcing the diagnosis to long term follow-up. Eur Arch Otorhinolaryngol. 2011;268:1407-1419. 